\title{
Front Matter: Volume 8138
}

, "Front Matter: Volume 8138," Proc. SPIE 8138, Wavelets and Sparsity XIV, 813801 (19 October 2011); doi: 10.1117/12.914804

SPIE Event: SPIE Optical Engineering + Applications, 2011, San Diego, California, SPIE. United States 


\section{PROCEEDINGS OF SPIE}

\section{Wavelets and Sparsity XIV}

Manos Papadakis

Dimitri Van De Ville

Vivek K. Goyal

Editors

21-24 August 2011

San Diego, California, United States

Sponsored and Published by

SPIE

Volume 8138

Proceedings of SPIE, 0277-786X, v. 8138 
The papers included in this volume were part of the technical conference cited on the cover and title page. Papers were selected and subject to review by the editors and conference program committee. Some conference presentations may not be available for publication. The papers published in these proceedings reflect the work and thoughts of the authors and are published herein as submitted. The publisher is not responsible for the validity of the information or for any outcomes resulting from reliance thereon.

Please use the following format to cite material from this book:

Author(s), "Title of Paper," in Wavelets and Sparsity XIV, edited by Manos Papadakis, Dimitri Van De Ville, Vivek K. Goyal, Proceedings of SPIE Vol. 8138 (SPIE, Bellingham, WA, 2011) Article CID Number.

ISSN 0277-786X

ISBN 9780819487483

Published by

SPIE

P.O. Box 10, Bellingham, Washington 98227-0010 USA

Telephone +1 3606763290 (Pacific Time) · Fax +1 3606471445

SPIE.org

Copyright (C) 2011, Society of Photo-Optical Instrumentation Engineers

Copying of material in this book for internal or personal use, or for the internal or personal use of specific clients, beyond the fair use provisions granted by the U.S. Copyright Law is authorized by SPIE subject to payment of copying fees. The Transactional Reporting Service base fee for this volume is $\$ 18.00$ per article (or portion thereof), which should be paid directly to the Copyright Clearance Center (CCC), 222 Rosewood Drive, Danvers, MA 01923. Payment may also be made electronically through CCC Online at copyright.com. Other copying for republication, resale, advertising or promotion, or any form of systematic or multiple reproduction of any material in this book is prohibited except with permission in writing from the publisher. The CCC fee code is 0277-786X/11/\$18.00.

Printed in the United States of America.

Publication of record for individual papers is online in the SPIE Digital Library.

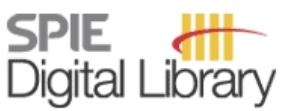

SPIEDigitalLibrary.org

Paper Numbering: Proceedings of SPIE follow an e-First publication model, with papers published first online and then in print and on CD-ROM. Papers are published as they are submitted and meet publication criteria. A unique, consistent, permanent citation identifier (CID) number is assigned to each article at the time of the first publication. Utilization of CIDs allows articles to be fully citable as soon as they are published online, and connects the same identifier to all online, print, and electronic versions of the publication. SPIE uses a six-digit CID article numbering system in which:

- The first four digits correspond to the SPIE volume number.

- The last two digits indicate publication order within the volume using a Base 36 numbering system employing both numerals and letters. These two-number sets start with $00,01,02,03,04$, $05,06,07,08,09,0 A, 0 B \ldots 0 Z$, followed by 10-1Z, 20-2Z, etc.

The CID number appears on each page of the manuscript. The complete citation is used on the first page, and an abbreviated version on subsequent pages. Numbers in the index correspond to the last two digits of the six-digit CID number. 


\title{
Contents
}

\author{
ix Conference Committee \\ xiii Introduction
}

\section{KEYNOTE SESSION}

813804 Sparse reconstruction of visual appearance for computer graphics and vision (Keynote Paper) [8138-38]

R. Ramamoorthi, Univ. of California, Berkeley (United States)

\section{SESSION 1 SPARSITY IN WAVEFIELDS: RADAR, ACOUSTIC, OPTICS AND EEG}

813806 SAR moving target imaging in a sparsity-driven framework [8138-01]

N. Ö. Önhon, M. Çetin, Sabanci Univ. (Turkey)

813807 Refractive index map reconstruction in optical deflectometry using total-variation regularization [8138-03]

L. Jacques, A. González, E. Foumouo, P. Antoine, Univ. Catholique de Louvain (Belgium)

813808 Compressively sampling the plenacoustic function [8138-04]

R. Mignot, Institut Langevin, CNRS, Univ. Paris Diderot. (France) and Institut Jean Le Rond d'Alembert, CNRS, Univ. Pierre et Marie Curie (France); G. Chardon, L. Daudet, Institut Langevin, CNRS, Univ. Paris Diderot (France)

\section{SESSION 2 FRAME THEORY AND APPLICATIONS I}

813809 Weighted- $\ell_{1}$ minimization with multiple weighting sets [8138-05]

H. Mansour, Ö. Yilmaz, The Univ. of British Columbia (Canada)

8138 0A Deterministic matrices with the restricted isometry property [8138-06]

M. Fickus, Air Force Institute of Technology (United States); D. G. Mixon, Princeton Univ. (United States)

$81380 \mathrm{C}$ Non-orthogonal fusion frames [8138-08]

J. Cahill, P. G. Casazza, Univ. of Missouri-Columbia (United States); S. Li, San Francisco State Univ. (United States)

8138 OD Grassmannians in frame theory [8138-09]

J. Cahill, Univ. of Missouri-Columbia (United States); S. Li, San Francisco State Univ. (United States) 
8138 OE Higher degree total variation (HDTV) algorithms for biomedical inverse problems [8138-10] Y. Hu, Univ. of Rochester (United States); M. Jacob, Univ. of lowa (United States)

8138 OF Tissue quantification in photon-limited microendoscopy [8138-11]

Z. T. Harmany, J. Mueller, Q. Brown, N. Ramanujam, R. Willett, Duke Univ. (United States)

$81380 \mathrm{G}$ Coherent source imaging and dynamic support tracking for inverse scattering using compressive MUSIC [8138-12]

O. Lee, J. M. Kim, J. Yoo, K. Jin, J. C. Ye, KAIST (Korea, Republic of)

$8138 \mathrm{OH} \quad$ Numerical evaluation of subsampling effects on image reconstruction in compressed sensing microscopy [8138-13]

Y. Le Montagner, URA, CNRS, Institut Pasteur (France) and LCTI, CNRS, Telecom ParisTech (France); E. Angelini, LCTI, CNRS, Telecom ParisTech (France); J.-C. Olivo-Marin, URA, CNRS, Institut Pasteur (France)

8138 Ol Fresnelab: sparse representations of digital holograms [8138-14]

M. Liebling, Univ. of California, Santa Barbara (United States)

SESSION 4 FRAME THEORY AND SPARSE APPROXIMATIONS I

8138 OK Joint sparsity models for wideband array processing [8138-16]

P. T. Boufounos, Mitsubishi Electric Research Labs. (United States); P. Smaragdis, Univ. of Illinois at Urbana-Champaign (United States); B. Raj, Carnegie Mellon Univ. (United States)

$81380 \mathrm{M}$ Uniqueness conditions for low-rank matrix recovery [8138-18]

Y. C. Eldar, Technion-Israel Institute of Technology (Israel); D. Needell, Stanford Univ. (United

States); Y. Plan, California Institute of Technology (United States)

\section{SESSION 5 NON-CONVENTIONAL IMAGING METHODS AND SPARSITY}

813800 Diffuse imaging: replacing lenses and mirrors with omnitemporal cameras [8138-20]

A. Kirmani, H. Jeelani, V. Montazerhodjat, V. K. Goyal, Massachusetts Institute of Technology (United States)

8138 OP Localization of point sources for systems governed by the wave equation [8138-21]

Z. Dogan, V. Tsiminaki, I. Jovanovic, Ecole Polytechnique Fédérale de Lausanne

(Switzerland) and Univ. of Geneva (Switzerland); T. Blu, The Chinese Univ. of Hong Kong

(Hong Kong, China); D. Van De Ville, Ecole Polytechnique Fédérale de Lausanne

(Switzerland) and Univ. of Geneva (Switzerland)

\section{SESSION 6 FRAME THEORY AND APPLICATIONS II}

$81380 Q \quad$ Frame completions for optimally robust reconstruction [8138-22]

M. Fickus, Air Force Institute of Technology (United States); D. G. Mixon, Princeton Univ.

(United States); M. J. Poteet, Air Force Institute of Technology (United States) 
8138 OR Geometric optimization on spaces of finite frames [8138-23]

N. Strawn, Duke Univ. (United States)

8138 OS Sparse dual frames in compressed sensing [8138-24]

S. Li, San Francisco State Univ. (United States); T. Mi, Y. Liu, Renmin Univ. of China (China)

8138 OT An uncertainty principle for functions defined on graphs [8138-25]

A. Agaskar, Y. M. Lu, Harvard Univ. (United States)

8138 OU A domain-knowledge-inspired mathematical framework for the description and classification of H\&E stained histopathology images [8138-26]

M. L. Massar, Air Force Institute of Technology (United States); R. Bhagavatula, Carnegie Mellon Univ. (United States); J. A. Ozolek, Children's Hospital of Pittsburgh (United States); C. A. Castro, Univ. of Pittsburgh (United States); M. Fickus, Air Force Institute of Technology (United States); J. Kovacevic, Carnegie Mellon Univ. (United States)

\section{SESSION 7 SPARSITY IN WAVEFIELDS: GEOSCIENCES}

8138 OV A modified, sparsity-promoting, Gauss-Newton algorithm for seismic waveform inversion [8138-27]

F. J. Herrmann, X. Li, A. Y. Aravkin, T. van Leeuwen, The Univ. of British Columbia (Canada)

$81380 \mathrm{X}$ Wavelets and wavelet-like transforms on the sphere and their application to geophysical data inversion [8138-29]

F. J. Simons, Princeton Univ. (United States); I. Loris, Univ. Libre de Bruxelles (Belgium);

E. Brevdo, Princeton Univ. (United States); I. C. Daubechies, Duke Univ. (United States)

8138 OY Mismatch and resolution in compressive imaging [8138-30]

A. Fannjiang, W. Liao, Univ. of California, Davis (United States)

\section{SESSION 8 SPARSE REPRESENTATIONS IN MULTIDIMENSIONS I}

$8138 \mathrm{OZ}$ Coarse quantization with the fast digital shearlet transform [8138-31]

B. G. Bodmann, Univ. of Houston (United States); G. Kutyniok, X. Zhuang, Univ. Osnabrück (Germany)

813810 Discrete shearlet transform: faithful digitization concept and its applications [8138-32] W.-Q. Lim, Univ. of Osnabrück (Germany)

SESSION 9 BASES, FRAMES, AND DICTIONARIES: DESIGNS FOR SPARSITY I

813811 On accelerated hard thresholding methods for sparse approximation [8138-34]

V. Cevher, Swiss Institute of Technology (Switzerland)

813812 Deblurring of Poissonian images using BM3D frames [8138-36]

A. Danielyan, V. Katkovnik, K. Egiazarian, Tampere Univ. of Technology (Finland) 
813816 Spectral tetris fusion frame constructions [8138-43]

P. G. Casazza, Univ. of Missouri-Columbia (United States); M. Fickus, Air Force Institute of Technology (United States); A. Heinecke, Univ. of Missouri-Columbia (United States);

Y. Wang, Z. Zhou, Michigan State Univ. (United States)

813817 Stable signal recovery from the roots of the short-time Fourier transform [8138-44]

B. G. Bodmann, C. L. Liner, Univ. of Houston (United States)

813818 Analysis of data separation and recovery problems using clustered sparsity [8138-45]

E. J. King, G. Kutyniok, X. Zhuang, Univ. Osnabrück (Germany)

\section{SESSION 11 SPARSITY AND FACE RECOGNITION}

8138 1A An experimental comparison of online object-tracking algorithms [8138-47]

Q. Wang, F. Chen, W. Xu, Tsinghua Univ. (China); M.-H. Yang, Univ. of California, Merced (United States)

SESSION 12 SPARSITY IN WAVEFIELDS: TOMOGRAPHY AND MRI

8138 1C Use of learned dictionaries in tomographic reconstruction [8138-49]

V. Etter, Ecole Polytechnique Fédérale de Lausanne (Switzerland); I. Jovanovic, Ecole Polytechnique Fédérale de Lausanne (Switzerland) and Univ. of Geneva (Switzerland); M. Vetterli, Ecole Polytechnique Fédérale de Lausanne (Switzerland)

8138 1D On structured sparsity and selected applications in tomographic imaging [8138-50] A. Pižurica, J. Aelterman, F. Bai, S. Vanloocke, H. Q. Luong, B. Goossens, W. Philips, Ghent Univ. (Belgium)

8138 1E Some proximal methods for CBCT and PET tomography [8138-51]

S. Anthoine, LATP, CNRS, Aix-Marseille Univ. (France); J. F. Aujol, UMR, CNRS, Univ. de Bordeaux 1 (France); Y. Boursier, CPPM, CNRS, Aix-Marseille Univ. (France); C. Melot, LATP, CNRS, Aix-Marseille Univ. (France)

8138 IF Sampling theorems and compressive sensing on the sphere [8138-52] J. D. McEwen, G. Puy, J.-P. Thiran, P. Vandergheynst, Ecole Polytechnique Fédérale de Lausanne (Switzerland); D. Van De Ville, Y. Wiaux, Ecole Polytechnique Fédérale de Lausanne (Switzerland) and Univ. of Geneva (Switzerland)

$81381 \mathrm{G}$ Compressed sensing in k-space: from magnetic resonance imaging and synthetic aperture radar [8138-53]

M. E. Davies, C. Du, S. I. Kelly, I. W. Marshall, G. Rilling, Y. Tao, The Univ. of Edinburgh (United Kingdom)

SESSION 13 SPARSE SAMPLING AND IMAGE RECONSTRUCTION IN MRI I

$813811 \quad$ Compressive sensing MRI with complex sparsification [8138-55]

Y. Dong, J. Ji, Texas A\&M Univ. (United States) 
8138 IK Paradigm-free mapping with morphological component analysis: getting most out of fMRI data [8138-58]

C. Caballero Gaudes, Univ. of Geneva (Switzerland) and Univ. Hospital of Geneva (Switzerland); D. Van De Ville, Univ. of Geneva (Switzerland), Univ. Hospital of Geneva (Switzerland) and Ecole Polytechnique Fédérale de Lausanne (Switzerland);

N. Petridou, Univ. of Nottingham (United Kingdom) and Univ. Medical Ctr. Utrecht (Netherlands); F. Lazeyras, Univ. of Geneva (Switzerland) and Univ. Hospital of Geneva (Switzerland); P. Gowland, The Univ. of Nottingham (United Kingdom)

$81381 \mathrm{M}$ Regularizing GRAPPA using simultaneous sparsity to recover de-noised images [8138-59] D. S. Weller, Massachusetts Institute of Technology (United States); J. R. Polimeni, Massachusetts General Hospital (United States) and Harvard Medical School (United States); L. Grady, Siemens Corporate Research (United States); L. L. Wald, Massachusetts General Hospital (United States) and Harvard Medical School (United States);

E. Adalsteinsson, V. K. Goyal, Massachusetts Institute of Technology (United States)

\section{SESSION 15 BASES, FRAMES, AND DICTIONARIES: DESIGNS FOR SPARSITY II}

8138 iN Learned dictionaries for sparse image representation: properties and results [8138-35] K. Skretting, K. Engan, Univ. of Stavanger (Norway)

8138 IP Learning hierarchical and topographic dictionaries with structured sparsity [8138-61] J. Mairal, Univ. of California, Berkeley (United States); R. Jenatton, G. Obozinski, F. Bach, Institut National de Recherche en Informatique et en Automatique, CNRS, ENS (France)

$81381 Q$ Design of a tight frame of 2D shearlets based on a fast non-iterative analysis and synthesis algorithm [8138-62]

B. Goossens, J. Aelterman, H. Luong, A. Pižurica, W. Philips, Ghent Univ. (Belgium)

8138 IR A diagonally-oriented DCT-like 2D block transform [8138-63]

I. W. Selesnick, Polytechnic Institute of New York Univ. (United States); O. G. Guleryuz,

DoCoMo Communications Labs. USA Inc. (United States)

\section{SESSION 16 NOVEL FILTER AND DICTIONARY DESIGNS}

8138 is Radio frequency (RF) transient classification using sparse representations over learned dictionaries [8138-64]

D. I. Moody, Los Alamos National Lab. (United States) and Univ. of Maryland (United States);

S. P. Brumby, K. L. Myers, N. H. Pawley, Los Alamos National Lab. (United States)

8138 IT Tight frame 6-band symmetric wavelets with limited redundancy [8138-65]

F. Abdelnour, Univ. of Pittsburgh (United States)

$81381 \mathrm{U}$ Sparse signal representations using the tunable Q-factor wavelet transform [8138-66]

I. W. Selesnick, Polytechnic Institute of New York Univ. (United States) 
$81381 \mathrm{~V}$ Blind linear models for the recovery of dynamic MRI data [8138-67]

S. G. Lingala, The Univ. of lowa (United States); Y. Hu, Univ. of Rochester (United States); M. Jacob, The Univ. of lowa (United States)

$81381 \mathrm{X}$ Sparse dictionary learning for resting-state fMRI analysis [8138-69]

K. Lee, P. K. Han, J. C. Ye, KAIST (Korea, Republic of)

\section{SESSION 18 SPARSE REPRESENTATIONS IN MULTIDIMENSIONS II}

8138 IY 3D discrete shearlet transform and video denoising [8138-70]

D. Labate, P. S. Negi, Univ. of Houston (United States)

813812 Efficient multiscale and multidirectional representation of 3D data using the 3D discrete shearlet transform [8138-71]

B. Goossens, H. Luong, J. Aelterman, A. Pižurica, W. Philips, Ghent Univ. (Belgium)

$813820 \quad$ Multicomposite wavelet estimation [8138-72]

G. R. Easley, System Planning Corp. (United States); D. Labate, Univ. of Houston (United States); V. M. Patel, Univ. of Maryland, College Park (United States)

813821 3D-rigid motion invariant discrimination and classification of 3D-textures [8138-73]

S. Upadhyay, Univ. of Houston (United States); S. Jain, The Johns Hopkins Univ. (United States); M. Papadakis, R. Azencott, Univ. of Houston (United States)

Author Index 


\title{
Conference Committee
}

\author{
Program Track Chair
}

Khan M. Iftekharuddin, The University of Memphis (United States)

Conference Chairs

Manos Papadakis, University of Houston (United States)

Dimitri Van De Ville, Ecole Polytechnique Fédérale de Lausanne

(Switzerland) and University of Geneva (Switzerland)

Vivek K. Goyal, Massachusetts Institute of Technology (United States)

Program Committee

Akram Aldroubi, Vanderbilt University (United States)

Radu V. Balan, University of Maryland, College Park (United States)

John J. Benedetto, University of Maryland, College Park (United States)

Bernhard G. Bodmann, University of Houston (United States)

Peter G. Casazza, University of Missouri-Columbia (United States)

Matthew C. Fickus, Air Force Institute of Technology (United States)

William T. Freeman, Massachusetts Institute of Technology (United States)

Onur G. Guleryuz, DoCoMo Communications Laboratories USA, Inc. (United States)

Ioannis A. Kakadiaris, University of Houston (United States)

Ilya A. Krishtal, Northern Illinois University (United States)

Gitta Kutyniok, Universität Osnabrück (Germany)

Demetrio Labate, University of Houston (United States)

Andrew F. Laine, Columbia University (United States)

Michael Liebling, University of California, Santa Barbara (United States)

Jean Christophe Olivo-Marin, Institut Pasteur (France)

Ivan W. Selesnick, Polytechnic Institute of New York University (United States)

Jean-Luc Starck, Commissariat à l'Énergie Atomique (France)

Michael Unser, Ecole Polytechnique Fédérale de Lausanne

(Switzerland)

Yves Wiaux, Ecole Polytechnique Fédérale de Lausanne (Switzerland)

Leslie Ying, University of Wisconsin-Milwaukee (United States) 
Session Chairs

Keynote Sessions

Vivek K. Goyal, Massachusetts Institute of Technology (United States)

Manos Papadakis, University of Houston (United States)

Demetrio Labate, University of Houston (United States)

1 Sparsity in Wavefields: Radar, Acoustic, Optics and EEG

Yves Wiaux, Ecole Polytechnique Fédérale de Lausanne (Switzerland)

Dimitri Van De Ville, Ecole Polytechnique Fédérale de Lausanne

(Switzerland)

2 Frame Theory and Applications I

Matthew Fickus, Air Force Institute of Technology (United States)

Peter G. Casazza, University of Missouri-Columbia (United States)

3 Applications of Sparse Representations in Bioimaging

Michael Liebling, University of California, Santa Barbara (United States)

Jean-Christophe Olivo-Marin, Institut Pasteur (France)

$4 \quad$ Frame Theory and Sparse Approximations I

Radu V. Balan, University of Maryland, College Park (United States)

Bernhard G. Bodmann, University of Houston (United States)

Gitta Kutyniok, Universität Osnabrück (Germany)

$5 \quad$ Non-Conventional Imaging Methods and Sparsity

Manos Papadakis, University of Houston (United States)

6 Frame Theory and Applications II

Peter G. Casazza, University of Missouri-Columbia (United States)

Matthew Fickus, Air Force Institute of Technology (United States)

$7 \quad$ Sparsity in Wavefields: Geosciences

Yves Wiaux, Ecole Polytechnique Fédérale de Lausanne (Switzerland)

Dimitri Van De Ville, Ecole Polytechnique Fédérale de Lausanne

(Switzerland)

8 Sparse Representations in Multidimensions I

llya A. Krishtal, Northern Illinois University (United States)

Demetrio Labate, University of Houston (United States)

9 Bases, Frames, and Dictionaries: Designs for Sparsity I

Onur G. Guleryuz, DoCoMo Communications Laboratories USA, Inc.

(United States)

Ivan W. Selesnick, Polytechnic Institute of New York University

(United States) 
10 Frame Theory and Sparse Approximations II

Radu V. Balan, University of Maryland, College Park (United States)

Bernhard G. Bodmann, University of Houston (United States)

Gitta Kutyniok, Universität Osnabrück (Germany)

11 Sparsity and Face Recognition

Ioannis A. Kakadiaris, University of Houston (United States)

12 Sparsity in Wavefields: Tomography and MRI

Yves Wiaux, Ecole Polytechnique Fédérale de Lausanne (Switzerland)

Dimitri Van De Ville, Ecole Polytechnique Fédérale de Lausanne (Switzerland)

13 Sparse Sampling and Image Reconstruction in MRI I

Leslie Ying, University of Wisconsin-Milwaukee (United States)

14 Sparse Representations on MRI

Aleksandra Pižurica, Universiteit Gent (Belgium)

15 Bases, Frames, and Dictionaries: Designs for Sparsity II

Onur G. Guleryuz, DoCoMo Communications Laboratories USA, Inc. (United States)

Ivan W. Selesnick, Polytechnic Institute of New York University (United States)

$16 \quad$ Novel Filter and Dictionary Designs

Vivek K. Goyal, Massachusetts Institute of Technology (United States)

17 Sparse Sampling and Image Reconstruction in MRI II

Leslie Ying, University of Wisconsin-Milwaukee (United States)

18 Sparse Representations in Multidimensions II

Ilya A. Krishtal, Northern Illinois University (United States)

Demetrio Labate, University of Houston (United States) 
Downloaded From: https://www.spiedigitallibrary.org/conference-proceedings-of-spie on 25 Apr 2023

Terms of Use: https://www.spiedigitallibrary.org/terms-of-use 


\section{Introduction}

Wavelets and Sparsity XIV is the latest in a series of conferences launched in 1993 in the then annual meeting of the SPIE (Society of Photographic Instrumentation Engineers). This series is one of the two oldest conference venues on atomic representations of signals and images of which SPIE has been a kind and hospitable host. The key feature of these decompositions is the combination of sparsity in the transform domain with the ability to capture local features in the spatial domain. In the eighteen years since this series was initiated, numerous theoretical and algorithmic contributions have been made in the field of signal and image analysis that have been highlighted in this conference. Initially the focus was on the design of wavelets filters. Recently, as the name of the conference indicates, the community and so our conference focuses more on the theory of sparse representations as a whole and not strictly from the viewpoint of wavelets. New areas of theoretical study have emerged or re-emerged, such as compressive sensing, fusion frames, and directional transforms, while their applications appear to open new perspectives in areas such as MR imaging, computer visualization, face recognition, cellular communications, dictionary-based machine learning and many others.

The present volume reflects the work presented in Wavelets and Sparsity XIV along the lines described above. This volume is a testament on how the domain of sparse representations is an exciting and dynamic one. We hope that the interested reader will find it to be a valuable reference source. Last but not least, we thank all the contributors of this volume, the invited speakers and presenters of Wavelets and Sparsity XIV, the special sessions organizers, Mrs. Darcey Maher Peterson who oversaw the editing of this volume and Ms. Megan Artz who helped with the organization of our meeting. Please visit us at www.waveletseries.org to stay tuned.

\section{Manos Papadakis \\ Dimitri Van De Ville Vivek Goyal}


Downloaded From: https://www.spiedigitallibrary.org/conference-proceedings-of-spie on 25 Apr 2023

Terms of Use: https://www.spiedigitallibrary.org/terms-of-use 